\title{
Attitude to Substance Abuse: Do Personality and Socio-Demographic Factors Matter?
}

\author{
Isaac Rahimian Boogar ${ }^{1, *}$; Sayed Mosa Tabatabaee ${ }^{2}$; Jalileh Tosi ${ }^{3}$ \\ ${ }^{1}$ Department of Clinical Psychology, Faculty of Psychology and Educational Sciences, Semnan University, Semnan, IR Iran \\ ${ }_{3}^{2}$ Department of Psychology, Payame Noor University, Semnan, IR Iran \\ 3 Department of Clinical Psychology, Semnan Branch, Researches and Sciences Azad University, Semnan, IR Iran \\ *Corresponding author: Isaac Rahimian Boogar, Department of Clinical Psychology, Faculty of Psychology and Educational Sciences, Semnan University, Semnan, IR Iran. Tel: + 98- \\ 2323623300, Fax:+98-2323626888, E-mail:i_rahimian@semnan.ac.ir
}

Received: December 9, 2013; Revised: January 27, 2014; Accepted: February 15, 2014

\begin{abstract}
Background:Substance abuse is a serious global problem that is affected by multiple psychosocial and socio-demographic factors. Objectives: This study aimed to investigate the leading factors in positive attitude and tendency toward substance abuse in terms of personality, socio-economic, and socio-demographic factors.

Patients and Methods: In a cross-sectional study, 200 college students (105 females and 95 males) residing in Damghan University dormitory in northeast of Iran were recruited by random sampling from March to July 2013. The participants were instructed and asked to complete the NEO FIVE-factor Inventory, the attitude to substance abuse scale, and the demographic questionnaire. Then data were analyzed by stepwise multiple regression employing PASW 18.

Results: Being male sexand neuroticism had a significant positive role in predicting positive attitude toward substance abuse in university students. In addition, agreeableness, conscientiousness, openness, and socio-economic status had a significant negative role in predicting tendency toward substance abuse $(\mathrm{P}<0.001)$. Extraversion had no significant role in prediction of positive attitude to substance abuse $(\mathrm{P}$ $>0.05)$.

Conclusions: Lower agreeableness, decreased conscientiousness, higher neuroticism, diminished openness, low socio-economic status, and male sex might make university students more inclined to substance abuse. Thus, it is reasonable to show the importance of these factors in tailored prevention programs.
\end{abstract}

Keywords: Substance-Related Disorders; Attitude; Personality; Population Characteristics

\section{Background}

Despite the longstanding history of substance related disorders in the world, it has become a serious global problem in recent times and is affected by psychosocial, economic, individual, familial, and political factors $(1,2)$. Substance abuse applies to the using of any psychoactive substances, licit, illicit, or medically prescribed drugs (3). Recent evidences show that prevalence of alcohol consumption and substance abuse, especially new drugs such as ecstasy, is increasing among Iranian university students $(4,5)$. The multiplicity and interrelatedness of factors associated with substance abuse makes it a complex problem in health domain (6). The deteriorating effects of substance abuse on psychosocial functions, quality of life, and global health necessitate identifying the leading factors in tendency to substance abuse. Among the main factors, personality traits, socio-economic, and demographic factors have a significant role in tendency toward abusing different kinds of substances or drugs (2, $7,8)$.

Personality traits in the field of substance abuse have been the matter of interest in many studies. According to the previous studies, personality traits have significant effects on substance abuse disorders and related psychiatric symptomatology (9). Young adults with alcohol consumption have higher level of neuroticism and lower level of agreeableness in comparison to those who have never consumed the alcohol in terms of the "Big Five personality traits" theory (10). Personality traits along with prosaically risk-taking behaviors and familial factors affect the positive attitude toward engaging in the substance abuse behaviors (8). According to the conceptualization of the Big Five model, personality traits not only affect initiation of substance abuse, but also influence maintaining abstinence from substance abuse after 12-month follow-up (11). One relevant study showed significant associations among the Big Five personality traits and positive attitudes as well as engaging in unhealthy behaviors such as smoking and drug abuse in college students (12). Most evidences indicate that in comparison with some favorable personality traits such as conscientiousness, destructive personality traits such as neuroticism predispose to positive attitudes to substance abuse (ASA) (13-15).

On the other hand, socio-demographic and socio-eco- 
nomic determinants are associated with positive ASA (2, $16,17)$. Sex also effects the attitude; in other words, boys are more susceptible to substance abuse than girls are $(18,19)$. Lower education levels and low socio-economic status (SES) may result in tendency toward substance abuse and its perpetuation $(17,20)$. Marriage has been quoted as a protective factor against substance abuse, with higher rates of substance abuse and substance dependence among separated or divorced individuals or those who have never married $(21,22)$. This attitude was prominently affected by familial status along with marital conditions (3) and socio-demographic factors $(22,23)$. In addition, substance abuse is influenced by age, an important factor among demographic characteristics (24). In a recent study, Zayats et al. (21) found a reciprocal interaction between personality traits, age, and marital status and risks of abuse and dependency to the cocaine and nicotine.

Surprisingly, there is no original study that has comprehensively and concurrently evaluated the role of the personality traits, SES, and socio-demographic factors in the prediction of ASA in Iranian university students. Increasing the knowledge about the abovementioned factors is fundamental to preventive intentions, planning, and execution of the tailored substance abuse preventive strategies for university students.

\section{Objectives}

This research aimed to investigate leading factors in positive ASA via multidimensional determinants including personality traits, SES, and socio-demographic factors. Thus, the main question this study aimed to answer was "Do personality and socio-demographic factors matter in ASA?"

\section{Patients and Methods}

This research was a cross-sectional descriptive study and the study population was residing students in Damghan University dormitory in north east of Iran. Among this population, 200 university students with bachelor's degree (105 females and 95 males) and mean age of $24.63 \pm$ 6.24 years (range, 17-34) were recruited by random sampling from March to July 2013. Students who could effectively participate in the study and completely answer the instruments, had healthy physical/psychological conditions, without a history of current substance/drug dependency and abuse, proper psycho-social functions, good scholastic function, and sound well-being were included. Students with medical diseases/psychiatric disorders existence or flare-up, those who had received treatments or were hospitalized during the research period, and those with concurrent psychosocial problems were excluded. At first, among the initial 215 participants, nine cases were excluded for incorrect and rudimentary answering to the questions. Moreover, six cases were excluded because they had not met the inclusion criteria. Thus, fi- nal sample included 200 participants. The Postgraduate Research Committee in Researches and Sciences University, Semnan Branch, approved the study protocol. The study was derived from the dissertation of a Master of Art degree in clinical psychology, which was conducted in a five-month period.

\subsection{Instruments}

Participants were instructed to complete the NEO-Five Factor Inventory (NEO-FFI), the attitude to substance abuse scale (ASAS), and the demographic questionnaire.

The NEO-FFI contains 60 items and its full completion takes ten to 15 minutes (25). The NEO-FFI assesses the Big Five personality traits including neuroticism, extraversion and openness to experience, agreeableness, and conscientiousness. The NEO-FFI can be administered to those between 16 and 65 years of age with reading skills of at least sixth grade. High correlation has been reported between domains of NEO-FFI and similar measures such as personality research form, The Minnesota multiphasic personality inventory (MMPI), and Eysenck personality inventory $(25,26)$. Inter-informant reliability scores for all domains of the NEO-FFI were 0.68 to 0.78 , which indicated good to excellent scores. Intra-informant reliability was excellent for all domains with scores ranging from 0.84 to 0.96 . In addition, internal consistency of all domains was good (26). NEO-FFI has appropriate psychometric characteristics in Iranian samples (27).

The ASAS was constructed and validated by Delavar et al. (28). This scale includes 40 items in five-point Likert scale ranging from zero (completely disagree) to four (completely agree) and has three subscales for assessing the attitudes toward effects of substances abuse, tendency toward substances abuse, and attitudes toward dangers of substances abuse. The validity of the scale was confirmed by factor analysis (28). Internal consistency coefficient of aforementioned subscales was $0.90,0.91$, and 0.81 , respectively, and reliability during 14 to 25 days was 0.84 , 0.86 , and 0.85 , respectively. These figures confirm the consistency and reliability of this scale (17). In another study, Cronbach's $\alpha$ was $0.82,0.85$, and 0.90 for subscales, respectively, and 0.89 for total scale (29).

The study researchers designed a demographic questionnaire to record the demographic characteristics including age, sex, literacy, SES, and marriage status. Moreover, it was used for assessing the eligibility criteria such as possible history of psychopathologies and serious medical conditions, history of previous substance abuse, and daily psychosocial dysfunctions. Demographic data were collected through face-to-face interview about these variables. After explaining the study aims and procedures to participants and completing the sampling process, they were encouraged to answer the self-administrated inventories. In some cases, instruments were completed in second session due to insufficient time, participants being busy, and settings of administration. This study 
was conducted with regard to the ethical issues and guidelines of ethic committees including declaration of Helsinki. In addition, informed consent was obtained from participants. The authors declared no conflict of interest. Data were analyzed by descriptive statistics and multiple regression with stepwise method by PASW v.18 (IBM Corp., Somers, NY, USA). The multiple regression is a well-established statistical analysis for evaluating the predictive role of various variables in a continuous criterion variable (30). In this study, $\mathrm{P}<0.05$ was considered as statistically significant.

\section{Results}

The mean age of participants was $24.63 \pm 6.24$ years (range, 17-34). Among 200 participants, 95 were male (47.5\%) and 105 were female (52.5\%). In addition, there were 86 participants (43\%) with low, 65 (32.5\%) with moderate, and 49 (24.5\%) with high SES. Regarding highest familial literacy level (familial literacy mode), 12 participants (6\%) lived in illiterate families, 16 (8\%) in families with elementary literacy, 26 (13\%) in families with guidance level, 35 (17.5\%) in families with diploma level, 51 (25.5\%) in families with graduate level, 40 (20\%) in families with bachelor level, and 20 (10\%) in families with Master of Art level or higher. In terms of marriage status, 141 participants (70.5\%) were single and the remaining 59 (29.5\%) were married.

Firstly, before the regression analysis, results revealed no violation of the hypothesis of homoscedasticity and normality, multicollinearity/collinearity, and linear- ity. Collinearity statistics by tolerance was between 0.69 and one and by variance inflation factor (VIF) was between one and 1.51. In addition, Durbin-Watson statistic for rejecting the hypothesis of residual correlates was equivalent to 2.52. These figures showed that hypothesis of linear regression were established. Correlation matrix among determinants and criterion variable and mean \pm SD of continuous variables are presented in Table 1 .

Regarding the associations of positive ASA in university students with Big Five personality traits, the Pearson correlation coefficients revealed the followings: association of positive ASA with neuroticism, $\mathrm{r}=0.49$, and $\mathrm{P}=0.001$; extraversion, $\mathrm{r}=-0.25$, and $\mathrm{P}=0.001$; openness, $\mathrm{r}=-0.43$, and $\mathrm{P}=0.001$; agreeableness, $\mathrm{r}=-0.54$, and $\mathrm{P}=0.001$; and conscientiousness, $\mathrm{r}=-0.53$, and $\mathrm{P}=0.001$. Moreover, there was a statistically significant correlation between positive ASA and categorical predictors of $\operatorname{sex}(\mathrm{r}=0.21$ and $\mathrm{P}<0.01)$ as well as SES $(\mathrm{r}=-0.25$ and $\mathrm{P}<0.001)$ (Table 2 ).

Significant predictors were introduced in six steps into the linear regression model with stepwise method. Agreeableness was entered at first step that explained $42 \%$ of the variation in positive ASA $(\mathrm{F} 1,198=81.20, \mathrm{P}<0.001)$. In the step 2, agreeableness and conscientiousness were entered in the model, which explained $49 \%$ of the variation (F2, $197=59.27, \mathrm{P}<0.001)$. In the step 3, agreeableness, conscientiousness, and neuroticism were entered in the regression model that communally explained $56 \%$ of the variation $(\mathrm{F} 3,196=47.15, \mathrm{P}<0.001)$. In the step 4 , agreeableness, conscientiousness, neuroticism, and openness were entered in this model that collectively explained

\begin{tabular}{|c|c|c|c|c|c|c|c|c|c|c|}
\hline & $\mathbf{1}$ & 2 & 3 & 4 & 5 & 6 & 7 & 8 & 9 & 10 \\
\hline Attitude to substance abuse & - & - & - & - & - & - & - & - & - & - \\
\hline Male & $0.21^{\mathrm{a}}$ & - & - & - & - & - & - & - & - & - \\
\hline Literacy & -0.07 & $0.20^{\mathrm{a}}$ & - & - & - & - & - & - & - & - \\
\hline Marriage status & 0.08 & 0.07 & $-0.26^{b}$ & - & - & - & - & - & - & - \\
\hline Socio-economic status & $-0.25^{b}$ & 0.04 & 0.08 & 0.06 & - & - & - & - & - & - \\
\hline Age & 0.05 & $-0.20^{a}$ & $-0.35^{b}$ & $0.50^{b}$ & -0.07 & - & - & - & - & - \\
\hline Neuroticism & $0.49^{b}$ & 0.06 & $-0.05^{a}$ & -0.08 & $-0.20^{a}$ & -0.07 & - & - & - & - \\
\hline Extraversion & $-0.25^{b}$ & -0.06 & -0.07 & -0.09 & $0.17^{\mathrm{a}}$ & $-0.15^{a}$ & $-0.46^{b}$ & - & - & - \\
\hline Openness & $-0.43^{b}$ & 0.05 & -0.07 & $0.12^{\mathrm{a}}$ & $0.14^{\mathrm{a}}$ & $0.18^{\mathrm{a}}$ & $-0.21^{\mathrm{a}}$ & 0.08 & - & - \\
\hline Agreeableness & $-0.54^{b}$ & $0.13^{\mathrm{a}}$ & -0.08 & $-0.17^{\mathrm{a}}$ & 0.06 & $-0.16^{a}$ & $-0.41^{b}$ & $0.54^{b}$ & $0.19^{\mathrm{a}}$ & - \\
\hline Conscientiousness & $-0.53^{b}$ & $0.12^{\mathrm{a}}$ & -0.09 & 0.06 & 0.08 & -0.07 & $-0.46^{b}$ & $0.39^{\mathrm{b}}$ & $0.12^{\mathrm{a}}$ & $0.52^{b}$ \\
\hline
\end{tabular}

\footnotetext{
${ }_{\mathrm{a}} \mathrm{P}<0.01$.
}

$\mathrm{b}_{\mathrm{P}}<0.001$.

Table 2. Mean of the Big Five Personality Traits Scores in Participants $(n=200)^{a}$

\begin{tabular}{lcccccc}
\hline & Attitude to Substance Abuse & Neuroticism & Extraversion & Openness & Agreeableness & Conscientiousness \\
\hline Results & $84.90 \pm 10.17$ & $24.31 \pm 7.05$ & $27.32 \pm 7.11$ & $24.08 \pm 4.67$ & $29.22 \pm 6.20$ & $31.17 \pm 8.61$ \\
\hline
\end{tabular}

a Data are presented as Mean \pm SD. 
$62 \%$ of the variation $(\mathrm{F} 4,195=39.58, \mathrm{P}<0.001)$. In the step 5 , agreeableness, conscientiousness, neuroticism, openness, and SES were entered in the regression model that totally explained $68 \%$ of the variation (F5, 194 $=34.44, \mathrm{P}<$ 0.001). At the final model (step 6), agreeableness, conscientiousness, neuroticism, openness, SES, and sex were entered in the regression model that totally explained $73 \%$ of variation in positive ASA in this sample of university students $(\mathrm{F} 6,193=30.51, \mathrm{P}<0.001)$. Thus, total variation that was generally explained by this model was $61 \%\left(\mathrm{R}^{2}=\right.$ 0.03 , F change $6,193=6.212$, and $\mathrm{P}<0.004$ ). Coefficients of regression model in prediction of positive ASA are presented in Table 3.

Six variables of agreeableness, conscientiousness, neuroticism, openness, SES, and sex significantly predicted the positive ASA. In this regression model by stepwise method, $\mathrm{R}^{2}$ was $0.42,0.49,0.56,0.62,0.68$, and 0.73 for steps one through six, consecutively. In addition, $\mathrm{R}^{2}$ was equal to $0.12,0.09,0.06,0.04$, and 0.03 for step two through six, consecutively $(\mathrm{P}<0.05)$. In this model, the variable of extraversion was excluded and did not have significant role in prediction of the ASA in university students $(\mathrm{P}>0.05)$.

\section{Discussion}

The results of this study indicated that tendency toward substance abuse in these participants was significantly affected by agreeableness, conscientiousness, neuroticism, openness, SES, and sex. In agreement with the preceding researchers $(8,9,14,25)$, personality traits especially neuroticism, agreeableness, conscientiousness, and openness have significant role in prediction of the ASA in college students. In different study designs, Wood

\begin{tabular}{|c|c|c|c|c|c|}
\hline & B & $\mathbf{S E}_{\mathrm{B}}$ & $\beta$ & $\mathbf{t}$ & PValue \\
\hline \multicolumn{6}{|l|}{ Step 1} \\
\hline Agreeableness & -3.347 & 0.360 & $-0.56^{\mathrm{a}}$ & -9.01 & $<0.001$ \\
\hline \multicolumn{6}{|l|}{ Step 2} \\
\hline Agreeableness & -2.814 & 0.383 & $-0.40^{\mathrm{a}}$ & -6.70 & $<0.001$ \\
\hline Conscientiousness & -2.055 & 0.304 & $-0.36^{b}$ & -6.17 & $<0.001$ \\
\hline \multicolumn{6}{|l|}{ Step 3} \\
\hline Agreeableness & -2.377 & 0.381 & $-0.34^{a}$ & -4.909 & $<0.001$ \\
\hline Conscientiousness & -2.124 & 0.308 & $-0.28^{b}$ & -3.869 & $<0.001$ \\
\hline Neuroticism & 1.916 & 0.339 & $0.26^{c}$ & 3.832 & $<0.001$ \\
\hline \multicolumn{6}{|l|}{ Step 4} \\
\hline Agreeableness & -2.248 & 0.377 & $-0.31^{a}$ & -4.50 & $<0.001$ \\
\hline Conscientiousness & -1.891 & 0.305 & $-0.31^{b}$ & -4.34 & $<0.001$ \\
\hline Neuroticism & 1.807 & 0.336 & $0.24^{c}$ & 3.41 & $<0.001$ \\
\hline Openness & -1.410 & 416 & $-0.20^{c}$ & -3.19 & $<0.001$ \\
\hline \multicolumn{6}{|l|}{ Step 5} \\
\hline Agreeableness & -2.003 & 0.372 & $-0.30^{b}$ & -4.56 & $<0.001$ \\
\hline Conscientiousness & -1.668 & 0.301 & $-0.29^{b}$ & -4.41 & $<0.001$ \\
\hline Neuroticism & 1.120 & 0.334 & $0.21^{\mathrm{c}}$ & 3.03 & $<0.002$ \\
\hline Openness & -1.234 & 0.323 & $-0.19^{c}$ & -2.97 & $<0.003$ \\
\hline Socio-Economic Status & -2.275 & 1.051 & $-0.18^{c}$ & -2.84 & $<0.005$ \\
\hline \multicolumn{6}{|l|}{ Step 6} \\
\hline Agreeableness & -2.194 & 0.299 & $-0.29^{b}$ & -4.43 & $<0.001$ \\
\hline Conscientiousness & -1.150 & 0.285 & $-0.22^{C}$ & -4.26 & $<0.001$ \\
\hline Neuroticism & 0.953 & 0.232 & $0.20^{\mathrm{C}}$ & 3.24 & $<0.002$ \\
\hline Openness & -0.901 & 0.308 & $-0.18^{c}$ & -2.92 & $<0.003$ \\
\hline Socio-Economic Status & -2.874 & 1.103 & $-0.18^{c}$ & -2.90 & $<0.004$ \\
\hline Sex & -3.007 & 1.812 & $-0.15^{a}$ & -2.49 & $<0.004$ \\
\hline
\end{tabular}

\footnotetext{
$\mathrm{a}_{\mathrm{P}}<0.001$.

$\mathrm{b}_{\mathrm{P}}<0.01$
}

${ }^{c} \mathrm{P}<0.05$. 
et al. (8) and Fridberg et al. (13) mentioned that substance abusers differ from others with respect to destructive personality traits and these traits are determining factors for positive ASA abuse in early adolescence and later life. Therefore, those with lower conscientiousness, agreeableness, and openness had higher tendency toward substance abuse than those with increased ones. Agreeableness, conscientiousness, and openness are healthy personality traits that positively affect the health tendencies for engagement in health behaviors. Therefore, these traits had negative correlation with tendency toward substance abuse. The specialists and clinicians who work in the field of substance abuse prevention and intervention must regularly assess personality traits. Some researches concerning the higher associations between personality traits (based on the big five model) and ASA have pointed to the complex and robust personalityaddiction connection and have suggested that the influence of personality traits on tendency toward substance abuse in college students should be evaluated regularly through the substance abuse preventive programs (21, 31, 32).

In accordance with the research evidences (2, 22, 33, 34), SES and sex had consequential effect on ASA in college students. According to Siziya et al. (17), adverse sociodemographic factors, especially inappropriate economic status, might affect ASA among school and college students via increasing the burden of psychosocial stress and precipitating or triggering the psychopathologies. On the other hand, Sorsdahl et al. concluded that there are differences in ASA in terms of sex and males are more inclined to engage in substance abuse than females (35). Moreover, Gupta et al. suggested that tendency to substance abuse is more prevalent among male college students than female ones (3). It may be concluded that low SES, especially among males, is the main contributor of tendency toward substance abuse. Therefore, improvement in the SES and adjustment to SES are main factors in reducing the positive ASA among college students. Moreover, ASA is influenced by sex differences because of males vulnerability to multiple environmental risk factors of substance abuse (19). In comparison to males, Iranian females have lower tendency toward substance abuse due to socio-cultural backgrounds that inhibits the girls from substance abuse. Based on these findings, it can be inferred that deteriorated SES and male sex are precipitating factors for substance abuse by increasing the tendency and inclination toward substances. Thus, during the execution the preventive agenda, considering these variables in initial and continuous assessment are necessary.

In contrast to most research evidences $(9,12,14)$, extraversion did not have significant effect on the ASA in college students. In a meta-analysis, Kotov et al. (9) revealed that persons with substance abuse disorders have low extraversion and this factor has significant role in tendency toward substance abuse. Therefore, according to the Zay- ats et al. (21), there is a complex and reciprocal interaction between extraversion and the risks of cocaine abuse and nicotine dependency. Nevertheless, the findings regarding the effects of extraversion on prediction of the ASA are controversial $(15,36)$. Extraversion in this study had an insignificant predictive role in ASA, which is in contrary to the majority of other studies. It might be due to socio-cultural differences in substance abusers, low sample size, different measurement, specific research methodology, distinctive study design, and existence of other principle predictors (e.g. neuroticism, conscientiousness, openness, and SES) in this regression model.

This was an initial study that aimed to evaluate the associations of personality trait and socio-demographic factors with positive ASA in a population of Iranian university students. However, the study results should be elucidated and generalized regarding several limitations. Using the self-administrated instruments for data collection, cross-sectional design, lack of clinical factors and biomarkers assessment, and sampling in the narrow spectrum might have affected and restricted the internal validation and generalization of the findings. We excluded those students with severe psychopathologies or profound deterioration in scholastic performance, which might have affected the study results. Therefore, further investigations about special groups of university students will disclose important facts with that regard. Eventually, as suggested by various authors $(3,30)$, investigating the principal determinants of tendency toward substance abuse in university students can help health specialists to design valid randomized controlled clinical trials for preventing the substance abuse in university students.

Eventually, in accordance with most studies, we conclude that lower agreeableness, decreased conscientiousness, higher neuroticism, diminished openness, inappropriate SES, and male sex can help to predict positive attitude and tendency toward substance abuse in university students. Thus, these leading factors should be considered in strategic planning and execution of tailored preventive programs concerning prevention of substance abuse in college students. Preventive policies that aim these factors would be capable of eliminating positive ASA in college students. In addition, identification and management of the psychosocial correlates of ASA in university students would be more noticeable and profitable.

\section{Acknowledgements}

Postgraduate Research Committee of Researches and Sciences University approved this study as thesis in Master of Art degree in Clinical Psychology. Authors genuinely express their gratitude to participants for their involvement in the research and staff of Damghan University Dormitory for providing assistance in the study coordination and execution. 


\section{Authors' Contributions}

Authors had same involvement in scheduling and programming the research design, study execution, data analysis, and writing the manuscript. All authors developed the original opinion and the study design. In addition, all authors analyzed the data and contributed to the writing the manuscript.

\section{Funding/Support}

This study was conducted by authors' expenses.

\section{References}

1. Vossius C, Testad I, Skjaeveland R, Nesvag S. The use and costs of health and social services in patients with longstanding substance abuse. BMC Health Serv Res. 2013;13:185.

2. Rather YH, Bashir W, Sheikh AA, Amin M, Zahgeer YA. Socio-demographic and Clinical Profile of Substance Abusers Attending a Regional Drug De-addiction Centre in Chronic Conflict Area: Kashmir, India. Malays J Med Sci. 2013;20(3):31-8.

3. Gupta S, Sarpal SS, Kumar D, Kaur T, Arora S. Prevalence, pattern and familial effects of substance use among the male college students -a north Indian study. J Clin Diagn Res. 2013;7(8):1632-6.

4. Amiri ZM, Shakib AJ, Moosavi AK. Prevalence and risk factors of ecstasy use among college students in Astara, Islamic Republic of Iran. East Mediterr Health J. 200 9;15(5):1192-200.

5. Baheiraei A, Hamzehgardeshi Z, Mohammadi MR, Nedjat S, Mohammadi E. Alcohol and drug use prevalence and factors associated with the experience of alcohol use in Iranian adolescents. Iran Red Crescent Med J. 2013;15(3):212-7.

6. Tavolacci ME, Ladner J, Grigioni S, Richard L, Villet H, Dechelotte $\mathrm{P}$, et al. Prevalence and association of perceived stress, substance use and behavioral addictions: a cross-sectional study among university students in France. BMC Public Health. 2013;13:724.

7. Saiz J, Alvaro JL, Martinez I. [Relation between personality traits and personal values in cocaine-dependent patients]. Adicciones. 2011;23(2):125-32.

8. Wood AP, Dawe S, Gullo MJ. The role of personality, family influences, and prosocial risk-taking behavior on substance use in early adolescence. J Adolesc. 2013;36(5):871-81.

9. Kotov R, Gamez W, Schmidt F, Watson D. Linking "big" personal ity traits to anxiety, depressive, and substance use disorders: a meta-analysis. Psychol Bull. 2010;136(5):768-821.

10. Coeffec A. [Big five-factor contributions to addiction to alcohol]. Encephale. 2011;37(1):75-82.

11. Betkowska-Korpala B. [Personality in the big five model and maintaining abstinence after one year follow-up]. Psychiatr Pol. 2012;46(3):387-99.

12. Raynor DA, Levine H. Associations between the five-factor mode of personality and health behaviors among college students. $J$ Am Coll Health. 2009;58(1):73-81.

13. Fridberg DJ, Vollmer JM, O'Donnell BF, Skosnik PD. Cannabis users differ from non-users on measures of personality and schizotypy. Psychiatry Res. 2011;186(1):46-52.

14. Solomon TM, Kiang MV, Halkitis PN, Moeller RW, Pappas MK. Personality traits and mental health states of methamphetaminedependent and methamphetamine non-using MSM. Addict Behav. 2010;35(2):161-3.

15. Jornet-Gibert M, Gallardo-Pujol D, Suso C, Andres-Pueyo A. Attitudes do matter: The role of attitudes and personality in DUI offenders. Accid Anal Prev. 2013;50:445-50.

16. McCann SJ. Subjective well-being, personality, demographic variables, and American state differences in smoking prevalence.
Nicotine Tob Res. 2010;12(9):895-904

17. Siziya S, Muula AS, Besa C, Babaniyi O, Songolo P, Kankiza N, et al. Cannabis use and its socio-demographic correlates among inschool adolescents in Zambia. Ital J Pediatr. 2013;39:13.

18. Liu D, Wang Z, Chu T, Chen S. Gender difference in the characteristics of and high-risk behaviours among non-injecting heterosexual methamphetamine users in Qingdao, Shandong Province, China. BMC public health. 2013;13:30.

19. Rienzi BM, McMillin JD, Dickson CL, Crauthers D, McNeill KF, Pesina MD, et al. Gender differences regarding peer influence and attitude toward substance abuse. J Drug Educ. 1996;26(4):339-47.

20. Marvanova M, Roumie CL, Eden SK, Cawthon C, Schnipper JL, Kripalani S. Health literacy and medication understanding among hospitalized adults.J Hosp Med. 2011;6(9):488-93.

21. Zayats T, Yang BZ, Xie P, Poling J, Farrer LA, Gelernter J. A complex interplay between personality domains, marital status and variant in CHRNA5 on the risks of cocaine, nicotine dependences and cocaine-induced paranoia. PLoS One. 2013;8(1).

22. Sarkar AP, Sen S, Mondal S, Singh OP, Chakraborty A, Swaika B. A study on socio-demographic characteristics of alcoholics attending the de-addiction center at Burdwan medical college and hospital in West Bengal. Indian journal of public health. 2013;57(1):33.

23. Safari Hajat Aghaii S, Kamaly A, Esfahani M. Meta-Analysis of Individual and Environmental Factors that Influence People's Addiction Tendencies. Int J High Risk Behav Addict. 2012;1(3):92-9.

24. Nasirzadeh M, Eslami AA, Sharifirad G, Hasanzadeh A. The mental health and substance abuse among youths aged 18 to 29: A comparative study. J Educ Health Promot. 2013;2:34

25. Costa Jr PT, McCrae RR, Dye DA. Facet scales for agreeableness and conscientiousness: a revision of tshe NEO personality inventory. Pers Individ Dif. 1991;12(9):887-98.

26. Archer N, Brown RG, Boothby H, Foy C, Nicholas H, Lovestone S The NEO-FFI is a reliable measure of premorbid personality in patients with probable Alzheimer's disease. Int J Geriatr Psychiatry. 2006;21(5):477-84.

27. Besharat MA, Behpajooh A, Poursharifi H, Zarani F. Personality and chronic fatigue syndrome: The role of the five-factor model. Asian J Psychiatr. 2011;4(1):55-9.

28. Delavar A, Alizadeh A, Rezaee AM. Construction and Standardization of an Instrument for Measuring Tehrani High School Students' Attitude towards Narcotics. Q J Educ. 2004;20(3):51-76.

29. Bahrami F, Moazedian A, Hossaini-Almaddani SA. The effectiveness of problem-solving and decision-making skills on redaction of positive attitudes in opium dependents. QJ of Res Addict. 2013;7(25):57-72.

30. Garson GD. Multiple Regression. Asheboro.NC: Statistical Associates; 2012.

31. Dennhardt AA, Murphy JG. Prevention and treatment of college student drug use: A review of the literature. Addict Behav 2013;38(10):2607-18.

32. Nikmanesh Z, Adrom M, Bakhshani NM. Minnesota multiphasic personalityinventory score as a predictor of addiction potentia in youth. Int J High Risk Behav Addict. 2012;2012(1, Spring):20-4.

33. Swendsen J, Conway KP, Degenhardt L, Dierker L, Glantz M, Jin R et al. Socio-demographic risk factors for alcohol and drug dependence: the 10-year follow-up of the national comorbidity survey. Addiction. 2009;104(8):1346-55.

34. Ghanbari HashemAbadi BA, Rasouli Azad M, Saed O. Prevalence, Patterns, and Socio-Demographic Correlates of Nicotine Use in a Sample of Iranian University Students. Int J High Risk Behav Addict. 2012;2012(1, Spring):25-31.

35. Sorsdahl K, Stein DJ, Myers B. Negative attributions towards people with substance use disorders in South Africa: variation across substances and by gender. BMC Psychiatry. 2012;12:101.

36. Zilberman ML, Tavares H, el-Guebaly N. Relationship between craving and personality in treatment-seeking women with substance-related disorders. BMC Psychiatry. 2003;3:1. 